\title{
Características socioeconômicas da produção e parâmetros de qualidade do leite cru refrigerada no Município de Santa Maria, RS, Brasil
}

Socioeconomic characteristics and quality parameters of chilled raw millk produced in Santa

Maria, RS, Brazil

Características socioeconómicas de la producción y parámetros de calidad de la leche cruda refrigerada en el Municipio de Santa Maria, RS, Brasil

\section{Resumo}

O presente estudo avaliou aspectos socioeconômicos das unidades produtoras de leite caracterizando a produção e a qualidade do leite de pequenas e médias propriedades da zona rural do município de Santa Maria/RS. O estudo foi realizado em três etapas: I. Georreferenciamento das propriedades alvo do estudo; II. Visita e aplicação do instrumento de coleta de informações; III. Determinação de parâmetros de qualidade do leite cru refrigerado através das análises físico-químicas e microbiológicas, incluindo densidade, teores de proteína, extrato seco desengordurado (ESD), lactose e cinzas, contagem padrão em placas (CPP). Observou-se que a produção leiteira no município de Santa Maria/RS está concentrada em duas principais macrorregiões. Foi possível verificar vulnerabilidades no manejo reprodutivo, sistema de produção predominante e controle de problemas sanitários reportados, dificultando a máxima eficiência, no entanto, os produtores também reconhecem o esforço realizado por entes locais através de ações que visam reduzir tais dificuldades como a incorporação de sistemas de manejo agroecológico. As perdas de leite acontecem em 13 dos 30 estabelecimentos rurais. Em relação a participação nos mercados, os produtores rurais foram classificados em grupos considerando-se o destino da produção (direta ou para a indústria), nível tecnológico (tecnificados ou pouco tecnificados) manejo adotado nas propriedades (sistemas de cria das vacas, ordenha e conservação do leite cru). Com a análise de componentes principais (ACP) foi demostrado pouca associação entre nível tecnológico e qualidade físico-química do leite. Em geral, as amostras dos leites das propriedades avaliadas atingiram os requisitos mínimos preconizados pela legislação brasileira para o leite cru refrigerado.

Palavras-chave: Composição do leite; Sistemas de produção; Manejo bovino leiteiro. 


\begin{abstract}
The present study evaluated socioeconomic aspects of milk producing farms, characterizing the production and quality of milk from small and medium farms in the rural area of the municipality of Santa Maria / RS. The study was carried out in three stages: I. Georeferencing of the target properties of the study; II. Visit and application of the information collection instrument; III. Determination of quality parameters of chilled raw milk through physicalchemical and microbiological analyzes, including density, protein content, defatted dry extract (ESD), lactose and ash, standard plate count (CPP). It was observed that milk production in the municipality of Santa Maria is concentrated in two main macro-regions. It was possible to verify vulnerabilities in reproductive management, the predominant production system and control of reported health problems, hindering maximum efficiency. Milk losses occur in 13 of the 30 rural establishments. In relation to market share, rural producers were classified into groups considering the destination of production (direct or for industry), technological level (technically or low-tech) management adopted on the properties (systems of cow breeding, milking and conservation of raw milk). The principal component analysis (PCA) showed little association between technological level and physical-chemical quality of milk. In general, the milk samples from the evaluated properties reached the minimum requirements recommended by Brazilian legislation for chilled raw milk.
\end{abstract}

Keywords: Milk composition; Production systems; Dairy cattle management.

\title{
Resumen
}

En este estudio evaluaron aspectos socioeconómicos de unidades productoras de leche, caracterizando la producción y calidad de la leche de pequeñas y medianas fincas del área rural del municipio de Santa María / RS. El estudio se llevó a cabo en tres etapas: I. Georreferenciación de las propiedades objetivo del estudio; II. Visita y aplicación del instrumento de recolección de información; III. Determinación de los parámetros de calidad de la leche cruda refrigerada mediante análisis físico-químico y microbiológico, incluyendo densidad, contenido proteico, extracto seco desgrasado (ESD), lactosa y cenizas, recuento total en placa (CPP). Se observó que la producción de leche en el municipio de Santa María del estado de Rio Grande del Sur se concentra en dos macro-regiones principales. Se pudo constatar la vulnerabilidad en el manejo reproductivo, los sistemas de producción predominantes y control de enfermedades, dificultando una máxima eficiencia, sin embargo, los productores reconocen el esfuerzo que realizan las entidades locales a través de acciones encaminadas a reducir dichos inconvenientes como la incorporación de sistemas de manejo agroecológico. Las pérdidas de leche ocurren en 13 de los 30 establecimientos rurales. En relación a la participación de mercado, los productores rurales se agruparon considerando el destino de la producción (directa o industria), el nivel tecnológico (técnico o poca tecnología) de manejo adoptado en las propiedades (sistemas de cría, ordeño y conservación de leche cruda). A través del análisis de componentes principales (PCA) se constató que hubo poca asociación entre el nivel tecnológico y la calidad físico-química de la leche. En general, las muestras de leche de las propiedades evaluadas alcanzaron los requisitos mínimos recomendados por la legislación brasileña para la leche cruda refrigerada.

Palabras clave: Composición de la leche; Sistemas de producción; Manejo bovino lechero.

\section{Introdução}

Uma das cadeias produtivas mais relevantes para agronegócio brasileiro é a do leite (Breitenbach \& Souza, 2015). Caracterizada como um sistema com interação constante, onde os diferentes elos se relacionam desde o produtor de insumos para a produção de leite até o consumidor final, necessita permanentemente de coordenação ao longo do processo (Breitenbach, et al., 2017). Ao mesmo tempo, reconhece-se um alto grau de diversidade em termos de sistemas de produção, capaz de envolver desde pequenos a grandes produtores; desde os que vendem o excedente até aqueles capitalizados, onde a atividade é predominante. Em face disso, também há uma diversidade de formas de organização tecnológicas e organizacionais, envolvendo infraestruturas de produção, rotas de coleta, modos de organização e relação com os mercados dentre outros.

O Estado de Rio Grande do Sul (RS) lidera em produtividade com 3.326 L/vaca/ano, ocupando o maior produtor de leite a nível do Brasil, com produção média de 11,2 L/vaca, de um total de 1,3 milhão de vacas ordenhadas (Governo do Estado de Rio Grande do Sul, 2019). O relatório anual da cadeia produtiva regional do leite do ano 2019 (EMATER, 2019), traz informações relevantes sobre os principais indicadores da produção incluindo aspectos tanto técnicos, quanto da organização dos produtores. Vale a pena mencionar alguns critérios para discriminar os diferentes sistemas produtivos como, por exemplo, o destino da produção, sistemas de pastoreio, conformação racial do rebanho, tipo de tecnologias utilizadas na produção e características da agroindústria processadora de leite. 
Estudos como o realizado por Picoli et al. (2015), contribuíram para compreender as estratégias de enfrentamento para os desafios da produção leiteira no estado de Rio Grande do Sul. Neste trabalho foi realizado um diagnóstico da situação da produção leiteira nos Municípios de Pelotas e Lagoa Costeira (RS), onde avaliaram os aspectos socioeconômicos e a influência sobre a qualidade do leite, associando o nível de educação à qualidade do leite e a deficiência em investimento e infraestrutura, assim como a importância das particularidades demográficas de uma região para compreender a relação positiva entre a escolaridade e o nível de adoção de tecnologias na produção. Neste contexto é importante também entender a dinâmica local de desenvolvimento e a relação da produção com os mercados. Em alguns lugares a comercialização surge através da interação entre produtores e consumidores (Silva, et al., 2017), e em outros pode acontecer pela inserção da produção em cadeias longas de comercialização, tipo dos mercados convencionais.

O município de Santa Maria, localizado na região central do Estado do Rio Grande do Sul, Brasil, pouco figura neste cenário da produtividade leiteira regional, contudo existem esforços e ações para elevar o nível produtivo, através da implementação de programas para a melhoria dos sistemas produtivos por meio de diversas instituições públicas e privadas (Winch, et al., 2019; Nunes \& Karnopp, 2013). De modo geral, verifica-se empiricamente que tem havido uma redução do número de estabelecimentos produtores, havendo duas tendências principais de produção. De um lado produtores que produzem com foco na comercialização para grandes cooperativas e empresas, e de outro, aqueles que buscam comercializar em mercados proximidade, seja in natura, ou processado artesanalmente. $\mathrm{O}$ acompanhamento em termos de assistência técnica e extensão rural é proporcionado principalmente pela Emater/RS-ASCAR.

Conhecer a realidade da produção leiteira é de vital importância para a implementação de qualquer programa de melhoria. A identificação das potencialidades, assim como as limitações e necessidades do setor leiteiro visam conduzir a garantia de uma produção de qualidade, seja para comercializar por meio de canais de mercados de cadeia longa, seja por meio de mercados de cadeia curta. Neste contexto, este trabalho teve como objetivo compreender a produção leiteira a partir da caracterização das unidades produtivas e da qualidade do leite produzido em estabelecimentos rurais do Município de Santa Maria, Estado do Rio Grande do Sul, Brasil. Dessa forma, o artigo está estruturado em três seções além dessa introdução. Os materiais e métodos descrevem a abordagem metodológica, os resultados estão divididos em quatro sub-seções e por último vem as considerações finais.

\section{Metodologia}

\subsection{Coleta de dados e amostras de leite}

$\mathrm{O}$ estudo se caracteriza como um estudo de caso, com abordagem de pesquisa quantitativa. Ela foi organizada em três momentos diferentes: I - A partir de informações do Escritório Municipal da Emater-RS/Ascar e da Prefeitura Municipal de Santa Maria, bem como de outros produtores, foi realizado o Georreferenciamento de 30 estabelecimentos rurais que foram identificados como produtores de leite nos distritos de Santa Maria; II - Visita e aplicação do instrumento de coleta de dados, organizado na forma de seções de análise (estabelecimento rural, mão-de-obra e atividade leiteira, sistemas de produção, instalações e equipamentos e qualidade do leite. Esses dois momentos da pesquisa foram realizados por conta do desenvolvimento da disciplina de Extensão Rural do Curso Técnico em Agropecuária do Colégio Politécnico da UFSM.

Para a análise da qualidade do leite, observando-se o protocolo de coleta de amostras preconizados pela legislação (Brasil, 2017), foram coletadas amostras de leite em recipientes previamente esterilizados, acondicionados em caixas de isopor contendo gelo sintético até seu translado para o Laboratório de Leites e Derivados na UFSM. III - Realização de análises físico-químicos e microbiológica das amostras coletadas em cada propriedade, de acordo com a IN 76 (BRASIL, 2018) sobre qualidade do leite, considerando os seguintes parâmetros físico-químicos: densidade, teores de proteína, extrato seco desengordurado (ESD), lactose e cinzas, quantificados com emprego de analisador ultrassónico de leite (Master Mini, AKSO) 
previamente calibrado; gordura através de analisador de gordura Milkotest (MK 1.5, ITR) calibrado com valores obtidos da análise de amostras com butirômetro. A crioscopia foi mensurada em crioscópio eletrônico digital microprocessado ITR MK 540 flex portátil. A acidez foi determinada por titulação com solução de hidróxido de sódio $(\mathrm{NaOH}) 0,1 \mathrm{~N}$ em presença de indicador de fenolftaleína (Brasil, 2017). Para avaliação da qualidade microbiológica considerou-se a contagem padrão em placas (CPP) de acordo com a IN 76 (Brasil, 2018), que contém os parâmetros de qualidade do leite cru refrigerado.

\subsection{Análise estatística dos dados}

Para determinar a variância dos parâmetros físico-químicos incluídos na caracterização das amostras de leite das propriedades involucradas no estudo foi utilizada a ferramenta de análise de componentes principais (ACP) usando o programa PAST (Hammer, et al., 2017).

\section{Resultados e Discussão}

\subsection{Caracterização do estabelecimento rural, mão de obra e atividade leiteira:}

Devido à relevância da cadeia produtiva leiteira para o agronegócio, é importante compreender as formas em que os elos e as interações entre os atores sociais relacionam-se dentro do processo produtivo, desde o produtor de insumos até o consumidor final (Breitenbach \& Souza, 2015; Breitenbach, et al., 2017).

Os dados gerais do estudo demonstram que referente ao gênero dos produtores ou responsáveis pelos estabelecimentos rurais analisados, 59\% são do sexo masculino e $41 \%$ do feminino. Estes dados corroboram com os dados publicados pelo IBGE (2017) em que a participação feminina aparece como minoritária, apesar de crescente.

Quanto ao nível de escolaridade, $68 \%$ dos produtores possuem o ensino fundamental completo, $7 \%$ possuem o ensino médio incompleto, $11 \%$ têm o ensino superior completo e 7\% não foram alfabetizados. Os dados de Picoli et al. (2015) indicam uma relação positiva entre o nível escolar e o nível de adoção de tecnologias na produção, indicando que produtores com maior grau de escolaridade pode ser um indicativo de maior nível tecnológico. Quanto ao núcleo familiar os entrevistados responderam ser constituído por 2 ou 3 integrantes, composto por um casal e um filho, ou outro membro da família.

Considerando o Município de Santa Maria, Estado do Rio Grande do Sul, Brasil, como ponto de referência, as propriedades rurais leiteiras visitadas estão localizadas entre 20 e $30 \mathrm{Km}$ de distância (54\%), 12\% há menos de $10 \mathrm{Km}$ de distância e $4 \%$ à mais de $30 \mathrm{Km}$. De acordo com o georreferenciamento das propriedades, foram identificados duas importantes microrregiões produtivas, reunindo a maior quantidade de produtores, identificadas como: MR-1 Santo AntãoBoca do Monte e MR-2 Pains-Arroio do Só-Palma, como pode ser observado na Figura 1. 
Figura 1: Geo-localização das propriedades leiteiras no Município de Santa Maria, Estado do Rio Grande do Sul, Brasil.

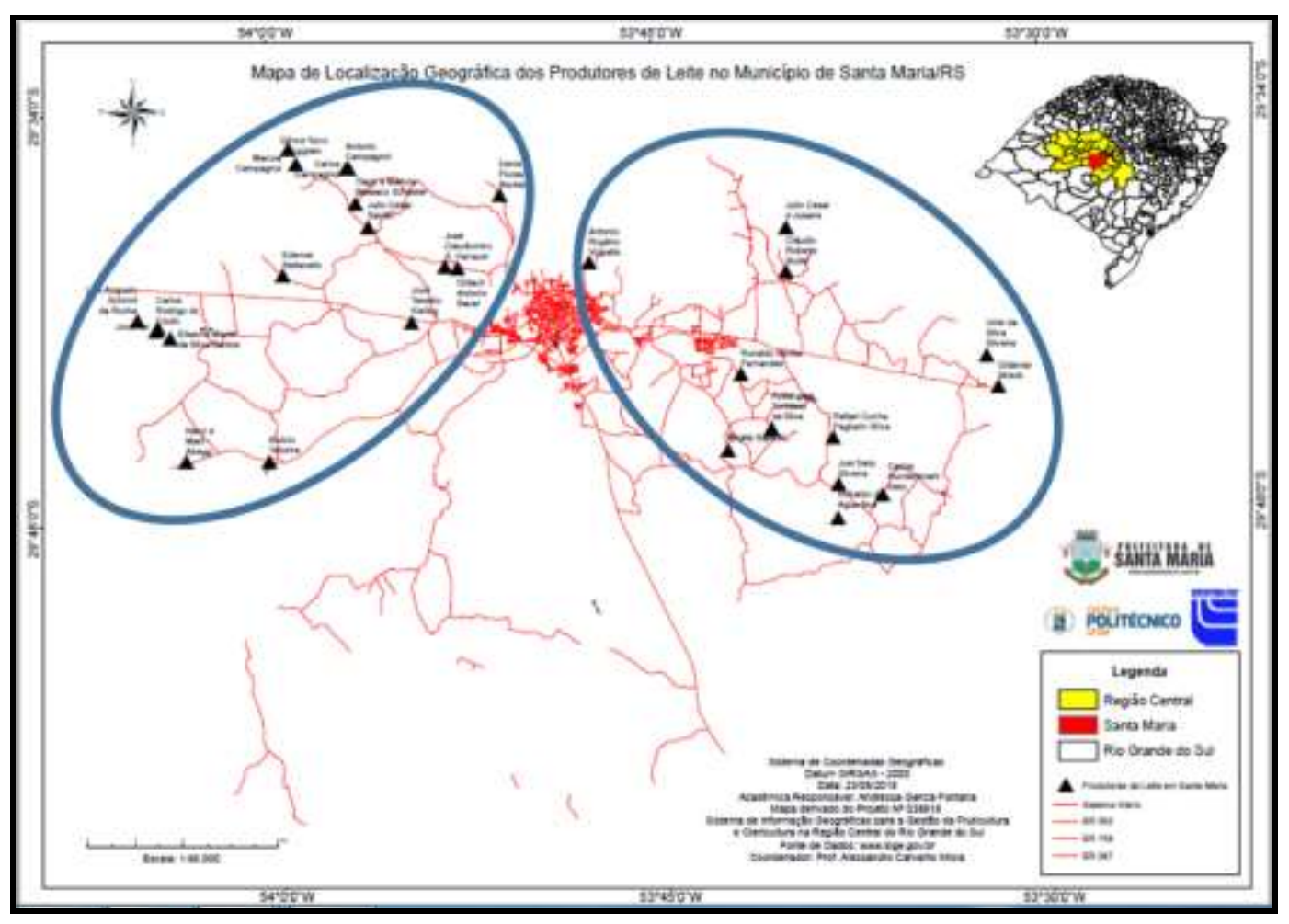

Fonte: GIPAG (2020).

O tamanho das propriedades variaram entre 25 a 50 ha (90\%) e mais de 50 ha (10\%). A média encontrada é superior ao apresentado por Picoli et al. (2015) na caracterização dos municípios de Pelotas e Lagoa Costeira do Rio Grande do Sul, Brasil. Considerando a estrutura fundiária e organização das propriedades agrárias nos estabelecimentos agropecuários do Estado e que foram mapeados pelo Censo Agropecuário em 2017, os resultados encontrados neste estudo também estão superiores: há em média $60 \%$ de propriedades com menos de 20 hectares no RS (IBGE, 2019).

Em relação a participação nas atividades da ordenha, $82 \%$ referem ser o responsável pela coleta do leite, no entanto, há a participação de outros membros da família. Infere-se, assim, que a mão-de-obra para realização dos trabalhos produtivos provém da própria família. A característica de uso de mão-de-obra familiar é recorrente no sul do Brasil, como refere o estudo de Werncke et at. (2016) sobre qualidade do leite e perfil das propriedades leiteiras no sul de Santa Catarina. Ainda, segundo os dados do estudo, $70 \%$ dos produtores consideram a produção leiteira como principal atividade geradora de renda, sendo esta atividade desenvolvida há mais de 30 anos.

\subsection{Caracterização do sistema de produção e instalações e equipamentos:}

Em relação à composição do rebanho, os estabelecimentos rurais estão constituídos por, em média, 16 vacas em lactação, 4 vacas secas, 6 novilhas, 4 terneiras e 3 terneiros. As raças predominantes são a Holandesa (45\%) e Jersey (41\%) e o restante por Gir, cruzamentos e raças não definidas. Estes resultados coincidem com o padrão racial identificado para todo o estado do Rio Grande do Sul (EMATER, 2019). Quanto ao manejo reprodutivo do rebanho, em sua maioria, é adotado somente a monta natural (44\%) ou inseminação artificial (41\%) e 15\% dos produtores dizem realizar a reprodução mista. Estes dados corroboram com resultados encontrados por Pires et al. (2018), em que a adoção da monta natural foi observada em dois terços das propriedades pesquisadas e uso de inseminação artificial comum ou em tempo fixo não era predominante. 
O sistema de produção predominante relatado foi caracterizado como a pasto (57\%) e o sistema de Pastoreio Racional Voisin (32\%). O Sistema Voisin foi considerado como experiência exitosa para ser apresentado em um e-book que reúne relatos de sucesso na revista digital da EMATER (EMATER/RS, 2018). 21\% se referiram a utilizar sistema de produção de semi-confinamento, todavia nesse caso, entende-se como a base de volumoso como silagem, e complementação com concentrado. Destaca-se a orientação para a produção de leite de base ecológica e a utilização do sistema Voisin como estratégias para melhorar a relação entre o humano-natureza através da reorganização dos sistemas, com a integração de componentes manejo de agroecossistemas, manejo agroecológico e bem estar animal (Belen \& Machado, 2019)

Sobre a utilização de sais minerais, mais de $70 \%$ administra o produto em misturas completas ou concentrado misturado com o sal mineral. Dados similares sobre o uso de suplementação mineral para rebanho leiteiro em propriedades da agricultura familiar foram encontrados por Pires et al. (2018). Nesse sentido, as técnicas de suplementação alimentar devem ser efetivas para obter bons índices de produtividade.

Os problemas sanitários reportados são referentes a presença de carrapatos e mastite. Como método preventivo da mastite, $46 \%$ dos produtores dizem usar tratamentos homeopáticos, $18 \%$ relatam a aplicação de antibióticos e $36 \%$ não manifestaram opinião nesta questão. Para identificar a presença de mastite, a maioria dos produtores utilizam o teste de raquete ou CMT (California Mastitis Test) (71\%), e o teste caneca de fundo preto; sendo realizadas cada mês (32\%), uma vez por semana (23\%), todos os dias (14\%) e em menor grau 1 vez cada 15 dias. Quanto à tuberculose, os testes são aplicados por 55\% ao menos uma vez por ano, pelos produtores consultados. E 30\% não tem conhecimento sobre o avanço desta doença, somente são informados quando as matrizes são vendidas.

A mastite bovina é recorrente em rebanhos leiteiros e acarreta prejuízos econômicos para os produtores e a indústria (Mesquita, et al., 2020). Segundo os autores, considerando o aspecto multifatorial da mastite e o potencial zoonótico, é de grande importância o conhecimento dos agentes envolvidos, etiologia e dos perfis de suscetibilidade aos antibióticos utilizados no tratamento dos rebanhos. Por sua vez, a tuberculose bovina continua sendo responsável por grandes perdas econômicas na pecuária, tanto em nível de produção primária quanto em termos de impactos no comércio de animais e seus produtos (Todeschini, et al., 2018).

Quanto ao método de ordenha mais utilizado, os resultados encontrados demonstram que $48 \%$ utilizam a balde ao pé e $33 \%$ utilizam a ordenha canalizada. Para refrigeração do leite, após a ordenha, $84 \%$ utilizam tanques de resfriamento de expansão, além de refrigeração à água e por imersão de tarro. Estes resultados são semelhantes aos obtidos por Reis (2019), onde as maiorias das propriedades pesquisadas utilizam ordenhadeira de tarro, ou "balde ao pé", com percentual de 44,79\% e a ordenhadeira canalizada 22,75\%. De acordo com o autor, esses números são compatíveis com o fato de a expressiva maioria das propriedades produzirem pequenos volumes diários de leite, o que dificulta ou impede o investimento em equipamentos mais sofisticados para a ordenha das vacas. Quanto aos resfriadores utilizados, o estudo do mesmo autor demonstrou que 96,01\% dos produtores de leite possuem resfriador de expansão direta e 3,62\% resfriadores de imersão (em tarros), apesar deste último não ser mais permitido pela regulamentação atual do Ministério da Agricultura.

Em $43 \%$ das propriedades analisadas, predominam, estábulo com piso, $36 \%$ possuem sala de ordenha com fosso ou rampa, e $21 \%$ apresentam estábulo com chão batido. Dados regionais mostram que 46,67\% dos produtores possuem sala de ordenha ou estabulo dotado de fosso ou rampa (EMATER, 2019). De acordo com a legislação as boas práticas agropecuárias devem estar de acordo na propriedade em relação as instalações, equipamentos e utensílios para produção de leite; (Brasil, 2018). 


\subsection{Caracterização do produtor quanto à qualidade do leite, gestão da propriedade e acesso aos mercados:}

A ocorrência de perdas de leite nos estabelecimentos rurais foi registrada em 13 dos 30 estabelecimentos rurais, que disseram acontecer uma vez por ano (55\%), 1 vez por semestre (36\%), ou 1 vez por mês (8\%). Segundo os agricultores essas perdas normalmente estão associadas a falta de energia elétrica (46\%); acidez do leite acima do limite (38\%); greve dos caminheiros (8\%); e quando por ocasião da aplicação de medicamentos. A garantia da qualidade do leite depende de vários fatores, desde o manejo na ordenha até a conservação do leite. As implicações de um manejo deficiente pode ser refletido na perda do produto e consequentemente na baixa renda (Múnera-Bedoya, et al., 2017).

Em relação à gestão da propriedade, a maioria dos produtores afirmam que é realizada pelo próprio grupo familiar. Dos entrevistados, $61 \%$ dizem fazer o registros de entradas e saídas de dinheiro através de anotações e $6 \%$ recebe apoio institucional para manejo de ferramentas de controle de gastos. O gerenciamento é uma ferramenta indispensável para o desenvolvimento sustentável do estabelecimento rural independente do seu tamanho (Pires, et al., 2018). Apesar de 33\% dos agricultores afirmarem não fazer controle, estamos diante de uma situação de busca de profissionalização e compreensão da atividade leiteira por meio do entendimento da composição dos gastos inerentes aos sistemas de produção.

Referente aos planos para os próximos cinco anos, $70 \%$ deseja aumentar a produção. Destes, $62 \%$ pretende investir recursos próprios e $17 \%$ pretende acessar algum tipo de financiamento. Em contrapartida, $21 \%$ consideram investir somente se houver melhora nos preços praticados pelo mercado. Dessa forma, verifica-se que os agricultores veem boas perspectivas na atividade leiteira, o que espera-se venha acompanhado pela profissionalização da atividade produtiva.

A produção de leite varia conforme o número de animais em lactação e foram estimadas entre 100 e 1.000 litros/dia e 3.0000 a 12.0000 litros/ano. O rendimento de litros de leite por vaca/dia variam entre 10 a 20 (48\%), de 20 a 25 (30\%), e entre 5-10 (15\%) e 7\% produz menos de 5 litros/dia.

A partir da análise das informações recolhidas nos instrumentos de coleta, os produtores rurais foram classificados em grupos considerando-se o destino da produção (venda direta para o consumidor ou para a indústria), nível tecnológico (tecnificados ou pouco tecnificados), manejo adotado nas propriedades (sistemas de cria das vacas, ordenha e conservação do leite cru). Apesar de ser difícil fazer uma avaliação de nível tecnológico, buscou-se construir uma classificação com base na infraestrutura disponível para a atividade, práticas de manejo e inovações tecnológicas. Em relação aos mercados definiu-se por seguir a tipologia de Schneider (2016), da qual deriva-se que os agricultores de Santa Maria ou estão nos mercados de proximidade, ou nos mercados convencionais. O mercado de proximidade pode ser entendido através dos mecanismos de circulação e distribuição dos produtos e mercadorias que ocorrem pelo deslocamento físico mais restrito possível e em um locus específico, sem a intermediação ao longo da cadeia produtiva (Schneider, 2016). Já o mercado convencional, é orientado pela oferta e demanda, tendo uma distribuição e circulação global e os mecanismos de intermediação passam a ser regidos por contratos, acordos, regulamentação de percentuais de ganhos e regras de uso e administração de direitos de propriedade (Schneider, 2016).

Dessa forma, foi possível verificar a seguinte disposição dos grupos de produtores rurais: Grupo 1 - Mercado de proximidade - Venda direta e consumo / Tecnificados (17,2\%): tratam-se de agricultores que vem fazendo investimentos e possuem uma infraestrutura adaptada para a produção de leite, com foco na comercialização de casa em casa, feiras livres ou no próprio estabelecimento rural; Grupo 2 - Mercado de proximidade - Venda direta e consumo / Pouco tecnificados (27,6\%): agricultores que tem outras atividades e que a produção normalmente é de baixa escala e de venda de forma direta, mas de maneira mais ocasional; Grupo 3 - Mercado convencional - Indústria / Tecnificados (20,7\%): produtores que produzem grandes volumes, infraestruturas adaptadas e comercializam para cadeia longa de comercialização; Grupo 4 - Mercado convencional - Indústria / Pouco tecnificados (34,5\%): produtores que comercializam na forma de cadeia longa, normalmente associando a produção com outras atividades. A Tabela 1 possibilita a composição dos grupos de produtores rurais quanto ao 
núcleo familiar, tamanho da propriedade, número do rebanho, número de vacas em lactação bem como a sua produção de leite diária e anual.

Tabela 1: Classificação dos produtores rurais do Município de Santa Maria, Estado do Rio Grande do Sul, Brasil, de acordo com o nível de tecnificação e destino da produção do leite.

\begin{tabular}{lllll}
\hline Item & G1 & G2 & G3 & G4 \\
\hline Produtores & 5 & 8 & 6 & 10 \\
Núcleo Familiar & 2 & 3 & 3 & 3 \\
Área (há) & 14,82 & 27,35 & 37,83 & 70,2 \\
Rebanho & 17 & 24 & 70 & 26,7 \\
Vacas em Lactação & 5 & 10 & 35 & 14,5 \\
Satisfação & Satisfeito (8) & Satisfeito (7) & Satisfeito (8) & Satisfeito (8) \\
Produção/vaca (litros) & 13,5 & 8,71 & 21,17 & 13,8 \\
Produção/dia (litros) & 90 & 57,57 & 731,67 & 176,5 \\
Produção/ano (litros) & 36132 & 35779 & 271650 & 59410 \\
Recebe assistência técnica & 4 & 8 & 7 & 7 \\
\hline
\end{tabular}

G1 - Grupo 1 Mercado de proximidade - Venda direta e consumo / Tecnificado, G2 - Grupo 2 - Mercado de proximidade - Venda direta e consumo / Pouco tecnificados; G3 - Grupo 3 - Mercado convencional - Indústria / Tecnificados; G4 - Grupo 4 - Mercado convencional Indústria / Pouco tecnificados. Fonte: Dados da pesquisa.

A média 5 de vacas em lactação e 90 L/dia de leite para os grupos 1 é ligeiramente superior aos resultados mostrados no relatório regional 2019, equivalente para produtores que comercializam leite cru diretamente para consumidores o qual foi de 4,05 vacas e 76,7 L/dia respectivamente (EMATER, 2019). O volume médio produzido pelos produtores deste grupo é ligeiramente superior à média regional de 76,7 L (EMATER, 2019).

\subsection{Análise de componentes principais (ACP) para os parâmetros físico-químicos do leite nas propriedades visitadas}

Na Tabela 2 são apresentados resultados das análises de amostras de leite de 18 das 29 propriedades alvo do estudo. Foram incluídas as médias dos parâmetros: gordura, extrato seco total (EST), extrato seco desengordurado (ESD), proteínas, lactose, cinzas, ponto crioscópico. 
Tabela 2: Parâmetros físico-químicos do leite cru refrigerado do leite de 18 propriedades no município de Santa Maria, Rio Grande do Sul, Brasil

\begin{tabular}{|c|c|c|c|c|c|c|c|c|c|c|}
\hline Grupo & $\begin{array}{c}\text { Produto } \\
\mathbf{r}\end{array}$ & $\begin{array}{c}\text { Gordura } \\
(\%)\end{array}$ & $\begin{array}{l}\text { ESD } \\
(\%)\end{array}$ & $\begin{array}{l}\text { EST } \\
(\%)\end{array}$ & $\begin{array}{c}\text { Densidade } \\
\text { (g/L) }\end{array}$ & $\begin{array}{l}\mathbf{P C} \\
\left({ }^{\circ} \mathbf{H}\right)\end{array}$ & $\begin{array}{c}\text { Proteína } \\
(\%)\end{array}$ & $\begin{array}{c}\text { Lactose } \\
(\%)\end{array}$ & $\begin{array}{c}\text { Cinzas } \\
(\%)\end{array}$ & $\begin{array}{c}\text { Acidez } \\
\left({ }^{\circ} \text { D) }\right.\end{array}$ \\
\hline \multirow{4}{*}{1} & 1 & 3,77 & 9,20 & 12,97 & 1,033 & $-0,525$ & 3,4 & 5,0 & 0,8 & 20,0 \\
\hline & 2 & 3,20 & 8,63 & 11,83 & 1,031 & $-0,509$ & 3,2 & 4,7 & 0,7 & 18,0 \\
\hline & 3 & 3,58 & 9,12 & 12,70 & 1,029 & $-0,583$ & 3,4 & 4,9 & 0,8 & 17,0 \\
\hline & 4 & 3,39 & 8,64 & 12,03 & 1,031 & $-0,523$ & 3,2 & 4,7 & 0,7 & 17,0 \\
\hline \multirow[t]{4}{*}{2} & 5 & 3,77 & 8,70 & 12,47 & 1,030 & $-0,527$ & 3,2 & 4,8 & 0,7 & 17,7 \\
\hline & 6 & 3,68 & 8,62 & 12,30 & 1,028 & $-0,527$ & 3,2 & 4,7 & 0,7 & 16,0 \\
\hline & 7 & 3,58 & 9,72 & 13,30 & 1,031 & $-0,540$ & 3,6 & 5,3 & 0,8 & 18,7 \\
\hline & 8 & 3,47 & 8,73 & 12,21 & 1,031 & $-0,516$ & 3,2 & 4,8 & 0,7 & 18,0 \\
\hline \multirow{6}{*}{3} & 9 & 3,23 & 9,00 & 12,23 & 1,032 & $-0,515$ & 3,3 & 4,9 & 0,7 & 18,0 \\
\hline & 10 & 3,50 & 9,18 & 12,67 & 1,033 & $-0,523$ & 3,4 & 5,0 & 0,8 & 18,0 \\
\hline & 11 & 3,23 & 9,00 & 12,23 & 1,032 & $-0,515$ & 3,3 & 4,9 & 0,7 & 18,0 \\
\hline & 12 & 3,41 & 8,83 & 12,24 & 1,031 & $-0,512$ & 3,3 & 4,8 & 0,6 & 19,3 \\
\hline & 13 & 4,18 & 8,78 & 12,96 & 1,030 & $-0,516$ & 3,3 & 4,8 & 0,7 & 16,7 \\
\hline & 14 & 3,10 & 8,40 & 11,49 & 1,030 & $-0,505$ & 3,1 & 4,6 & 0,7 & 16,7 \\
\hline \multirow[t]{4}{*}{4} & 15 & 4,87 & 9,37 & 14,24 & 1,032 & $-0,532$ & 3,5 & 5,1 & 0,8 & 17,0 \\
\hline & 16 & 3,38 & 8,52 & 11,90 & 1,030 & $-0,511$ & 3,1 & 4,7 & 0,7 & 15,7 \\
\hline & 17 & 3,17 & 8,93 & 12,10 & 1,032 & $-0,520$ & 3,3 & 4,9 & 0,7 & 18,3 \\
\hline & 18 & 3,55 & 8,55 & 12,10 & 1,030 & $-0,505$ & 3,2 & 4,7 & 0,7 & 15,0 \\
\hline
\end{tabular}

EST: extrato seco total; ESD: extrato seco desengordurado; PC: Ponto crioscópico; $D^{\circ}$ : acidez expresso em graus Dornic. Fonte: Dados da pesquisa.

Esta matriz de resultados foi submetida a análise de componentes principais (ACP), o qual permitiu visualizar a variância nos parâmetros físico-químicos das amostras analisadas (Gráfico 1). De todos os parâmetros avaliados, a acidez foi a que explicou a maior variância dentro do componente 1 (eixo horizontal), seguido pelos parâmetros do extrato seco total (EST) e a gordura que mostraram maior significância no componente 2 (eixo vertical). 
Gráfico 1: Análise de Componentes Principais (ACP) dos parâmetros físico-químicos avaliados nas amostras de leite dos produtores do município Santa Maria, RS, Brasil.

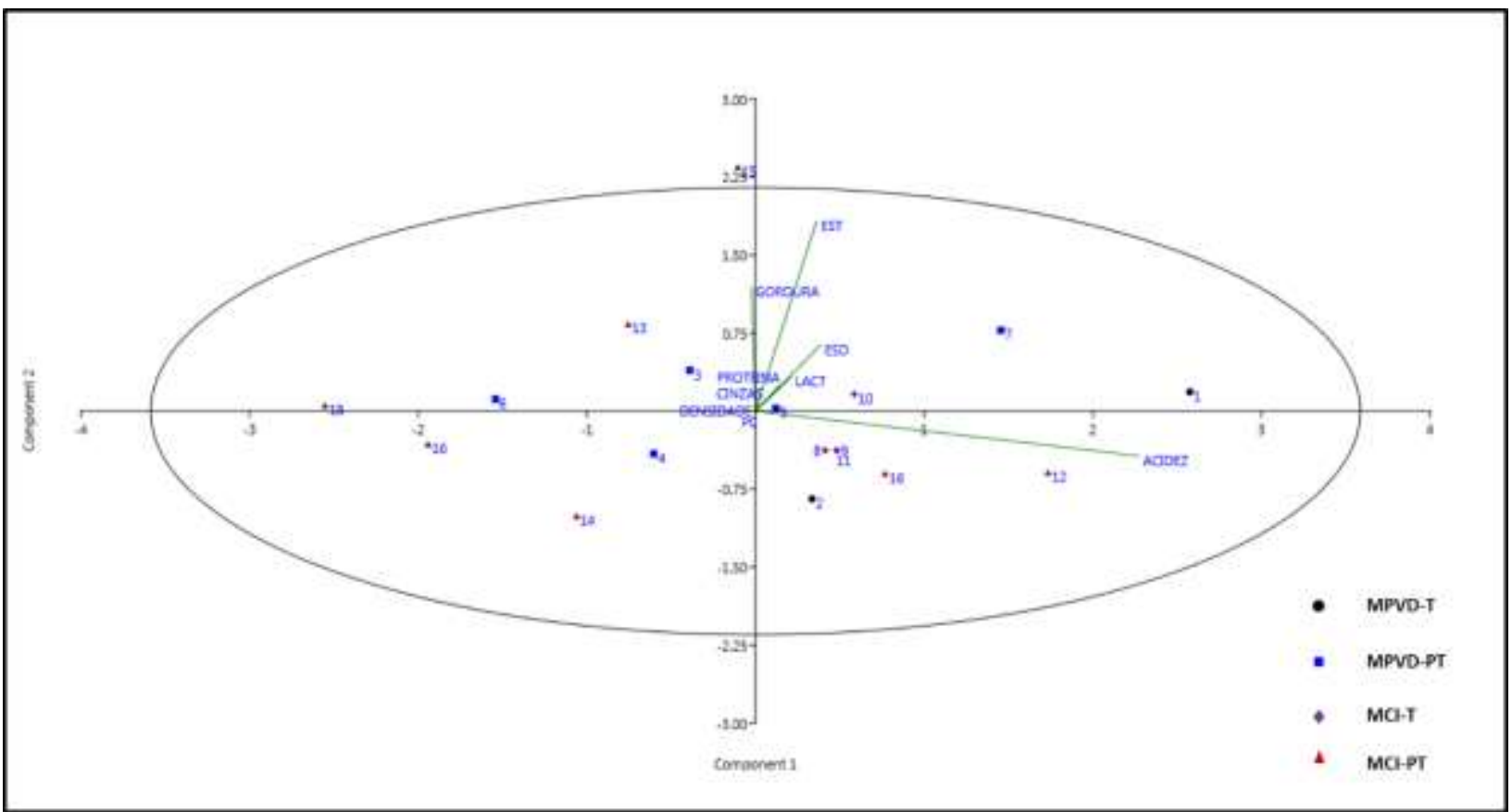

MPVD-T: Mercado de Proximidade/Venda Direta-Tecnificado (Grupo 1); MPVD-PT: Mercado de Proximidade/Venda Direta- Pouco Tecnificado (Grupo 2); MCI-T: Mercado Convencional/Industria-Tecnificado (Grupo 3); MCI-PT: Mercado Convencional/Industria-Pouco Tecnificado (Grupo 4). Fonte: Dados da pesquisa.

Em relação a acidez do leite, observou-se heterogeneidade dentre grupos 1, 2 e 4, isto quer dizer que produtores do mesmo grupo, mostraram diferenças entre eles, especialmente no grupo 2, onde $40 \%$ das amostras deste grupo tiveram valor de acidez maior do que o restante elementos dentro do grupo. Vale ressaltar que o grupo 2 se refere aos produtores que colocam sua produção direta para o consumidor através de venda na propriedade ou feiras livres (MPVD-PT), caracterizados também por possuir pouco nível de tecnológico dentro da sua propriedade. Segundo Vargas et al. (2019), a acidez do leite pode aumentar de acordo com a estação do ano como na primavera e no inverno, o aumento da Contagem de Bactérias Totais (CBT), também pode aumentar a acidez do leite devido ao aumento das bactérias mesófilas no leite, elevando-se com a utilização da lactose como principal substrato para esses microrganismos.

A introdução na propriedade leiteira de equipamentos como ordenhadeira mecânica, tanques de refrigeração, entre outros, deveria trazer uma melhoria na qualidade do leite, isto porque reduziria as possibilidades de contaminação do produto (Leira, 2018). No entanto, uma higienização deficiente dos equipamentos também pode ser decorrente de uma contaminação por acúmulo de sujidade, o que, poderia ter acontecido com o grupo 3. Este grupo representa os produtores que realizam venda do leite no mercado convencional ou indústria e que possui equipamentos nas propriedades (MCI-T).

Um aspecto interessante dentro do estudo foi que de todos os grupos conformados, o grupo 4 mostrou menores valores de acidez, ressaltando que são produtores que colocam a produção no mercado convencional-indústria, mas que possuem pouco nível de tecnificação dentro da propriedade (MCI-PT), o que pode indicar um leite com melhor qualidade, produto da aplicação de boas práticas de ordenha. Os resultados deste estudo coincidem com o trabalho realizado por Silveira et al. (2018), os quais não identificaram diferencias entre grupos de produtores com níveis tecnológicos sobre as características físico-química do leite em estudo sobre a Região do Semiárido no estado de Ceará.

O extrato seco total no leite é constituído por todos os componentes do leite exceto a água, ocupando entre $12 \%$ e $13 \%$ do peso total do leite. Este parâmetro pode variar de acordo com vários fatores, entre eles, a raça do animal, tipo de 
alimentação, estágio de lactação, sazonalidade, manejo do intervalo da ordenha ou estado de saúde do animal quando apresenta mastite, por exemplo (Brito, et al., 2020). Neste estudo, os menores valores de EST foram observados nos grupos 3 e 4, o que poderia estar associado a um manejo mais intensivo, comparado com os produtores dos grupos 1 e 2 . No entanto, todos os produtores estiveram acima do valor mínimo preconizado pela IN 76 (Brasil, 2018). De forma geral, a maioria dos produtores atingiram os requisitos de qualidade estabelecidos na IN 76 de 2018 (Brasil, 2018).

A qualidade microbiológica do leite foi determinada pela contagem padrão em placas de bactérias totais (CPP). A legislação vigente no momento da coleta e análise preconizava o máximo de 300 mil UFC/mL. Dos produtores que entregam sua produção para a indústria de lacticínios somente os do Grupo 3, mostraram valores dentro dos limites preconizados pela legislação (Brasil, 2018). O leite in natura, dependendo das boas práticas praticadas na propriedade rural, pode veicular agentes patogênicos que são responsáveis por doenças, podendo levar a óbitos. Quando as boas práticas são menosprezadas há uma probabilidade muito alta do leite conter patógenos, sendo que os surtos relacionados ao leite cru têm 150 vezes mais chances de ocorrer do que os surtos ocorridos com leite pasteurizado (Desmasures, et al., 1997). No entanto, nos últimos anos, o leite in natura tem se tornado cada vez mais popular por uma infinidade de razões, incluindo, presumivelmente, sabor e supostos "benefícios à saúde" das bactérias presentes no leite (Claeys, et al., 2013; Lucey, 2015). A pasteurização por calor afeta minimamente proteínas séricas, vitamina B12 e vitamina E, no entanto, não contribui significativamente para deficiências nutricionais (MacDonald, et al., 2011). Porém, produtores considerados tecnificados, mas que sua produção é comercializada de maneira direta, mostraram contagens altas (UFC mL ${ }^{-1}$ ). Picoli et al. (2014) concluíram que o grau de instrução dos produtores pode interferir na qualidade do leite, uma vez que encontraram uma correlação negativa em seu estudo.

Para avaliar a qualidade do leite, $57 \%$ dos produtores entrevistados manifestam contar com apoio das empresas para realização de análises microbiológicas, e 43\% realizam análises físico-químicas. A metade dos produtores afirmam que realizam algum teste de qualidade, e recebem apoio da indústria (87\%), através de algum comprador ou da Universidade Federal de Santa Maria (UFSM).

\section{Considerações Finais}

A produção leiteira no município de Santa Maria está concentrada em duas principais microrregiões identificados como MR-1 Santo Antão-Boca do Monte e MR-2 Pains-Arroio do Só-Palma. Os dados gerais demonstram que 59\% dos entrevistados são do sexo masculino, $90 \%$ têm entre 18 a 60 anos e $68 \%$ dos produtores possuem o ensino fundamental completo, o que possibilita relacionar o nível escolar e o nível de adoção de tecnologias na produção.

Quanto ao sistema de produção, os dados coletados possibilitam inferir que há vulnerabilidades referentes ao manejo reprodutivo adotado, sistema de produção predominante e controle de problemas sanitários reportados, colocando desafios para um processo de qualificação do sistema de produção.

Quanto à qualidade do leite, gestão da propriedade e acesso aos mercados, as perdas do leite nas propriedades estão associadas a problemas de gestão da propriedade (falta de energia elétrica, aplicação de medicamentos). É possível entender que o gerenciamento da propriedade rural seria uma ferramenta indispensável para o desenvolvimento local sustentável e para traçar estratégias de enfrentamento às adversidades dos sistemas de produção leiteira (clima, sazonalidade da produção, perecibilidade dos produtos e mão-de obra pouco qualificada).

Em relação ao acesso aos mercados, os produtores rurais foram classificados em grupos considerando-se o destino da produção (direta ou para a indústria), nível tecnológico (tecnificados ou pouco tecnificados) manejo adotado nas propriedades (sistemas de cria das vacas, ordenha e conservação do leite cru).

A análise de componentes principais (ACP) demonstrou baixa associação entre nível tecnológico e qualidade físicoquímica do leite, pois produtores que apresentavam um nível tecnológico maior possuíam maiores valores de acidez em 
comparação com os grupos de produtores que não possuem suficientes ferramentas tecnológicas dentro da propriedade. O tipo de sistema de produção poderia estar influenciando os teores de EST, como foi mostrado nos grupos que colocam sua produção na indústria. Em geral, as amostras dos leites das propriedades avaliadas atingiram os requisitos mínimos preconizados pela legislação brasileira para o leite cru refrigerado.

A aplicação de boas práticas se reflete em mudanças nos processos produtivos e no produto final, por tanto se sugere aplicar periodicamente questionários a fim de determinar qualquer tipo de melhoria ou determinar a eficiência das medidas implementadas e reavaliação dos grupos de produtores.

\section{Agradecimentos}

À Universidade Federal de Santa Maria (UFSM), Colégio Politécnico da UFSM, Empresa de Assistência Técnica e Extensão Rural (EMATER), Prefeitura Municipal de Santa Maria.

\section{Referências}

Borges, A. M., et al., (2015). Reprodução de vacas mestiças: potencialidade e desafios. Revista Brasileira de Reprodução Animal, 39(1), 155-163. www.cbra.org.br.

Brasil. Ministério da Agricultura, Pecuária e Abastecimento. (2018). Instrução Normativa 76 de 26 de novembro de 2018 . Dispõe sobre regulamentos técnicos de produção, identidade, qualidade, coleta e transporte do leite. Diário Oficial da União, Brasília, Seção 1, 30 nov. http://www.in.gov.br/materia//asset_publisher/Kujrw0TZC2Mb/content/id/52750137/do1-2018-11-30-instrucao-normativa-n-76-de-26-de-novembro-de-2018-52749894IN\%2076.

Brasil. Ministério da Agricultura, Pecuária e Abastecimento. Departamento de Inspeção de Produtos de Origem Animal (2018). Instrução Normativa nº 77, de 26 novembro de 2018. http://www.in.gov.br/materia/-/asset_publisher/Kujrw0TZC2Mb/content/id/52750141/do1-2018-11-30-instrucao-normativa-n-77-de26-de-novembro-de-2018-52749887.

Brasil. Ministério da Agricultura, Pecuária e Abastecimento (2017). Manual de métodos oficiais para análise de alimentos de origem animal / Ministério da Agricultura, Pecuária e Abastecimento. Secretaria de Defesa Agropecuária. - Brasília: MAPA, 2017.

Breitenbach, R., et al., (2017) Vantagens e oportunismo no relacionamento entre associados e cooperativa de laticínios. Interações 18.2. http://www.scielo.br/pdf/inter/v18n2/1518-7012-inter-18-02-0045.pdf.

Breitenbach, R., \& Souza, R. S. (2015). Estrutura, conduta e governança na cadeia produtiva do leite: um estudo multicaso no Rio Grande do Sul. Revista Eletrônica de Administração REAd, 82(3), 750-78, http://www.scielo.br/scielo.php?script=sci_arttext\&pid=S1413-23112015000300750.

Claeys, W. L. et al. (2013) Raw or Heated Cow Milk Consumption: Review of Risks and Benefits. FoodControl 31:251-262. http://hdl.handle.net/1854/LU4360262 .

Desmasures, N., Bazin, F., \& Gueguen, M. (1997). Microbiological composition of raw milk from selected farms in the Camembert region of Normandy. Journal of Applied Microbiology, 83(1), 53-58. http://doi.wiley.com/10.1046/j.1365-2672.1997.00166.x.

EMBRAPA, Empresa Brasileira de Pesquisa Agropecuária. Indicadores, tendências e oportunidades para quem vive no setor leiteiro. (2018). Anuário Leite 2018. https://www.embrapa.br/busca-de-noticias/-/noticia/36560390/anuario-do-leite-2018-e-lancado-na-agroleite.

Governo do Rio Grande do Sul. (2019). Radiografia da Agropecuaria Gaucha 2019. https://www.agricultura.rs.gov.br/secretaria-da-agricultura-apresentaradiografia-da-agropecuaria-gaucha-2019.

Hammer, O. (2017). Paleontological Statistics Version 3.15. Reference manual. Natural History Museum. University of Oslo., 253 p. https://folk.uio.no/ohammer/past/past3manual.pdf.

Leira, M. H. et al., (2018) Fatores que alteram a produção e a qualidade do leite: revisão. Pubvet, 12(5), 1-13. Editora MV Valero. doi.org/10.22256/pubvet.v12n5a85.1-13

Lopes. M. A Gestão na bovinocultura de leite. Ed. Ufla, 2015. 97p.

Lopes, M. A., \& Santos, G., (2012). Comparativo econômico entre propriedades leiteiras em sistema intensivo de produção: um estudo multicasos. Revista Brasileira de Saúde e Produção Animal, $13(3), 591-603$. http://www.scielo.br/scielo.php?script=sci_arttext\&pid=S $151999402012000300001 \& \operatorname{lng}=$ pt\&tlng=pt.

Lucey, J. A. (2015). Raw Milk Consumption: Risks and Benefits. Nutrition Today 50(4):189-193. https://journals.lww.com/nutritiontodayonlin e/Fulltext/2015/07000/Raw_Milk_Consumption_Risks_and_Benefits.10.aspx\#: :text=In\%20conclusion\%2C\%20raw\%20milk\%20is,poisoning\%20risk\%20 with $\% 20$ its $\% 20$ consumption.\&text=There $\% 20$ is $\% 20$ no $\% 20$ evidence $\% 20$ that,were $\% 20$ shown $\% 20$ to $\% 20$ be $\% 20$ myths.

MacDONALD, L. E.et al., (2011). A systematic review and meta-analysis of the effects of pasteurization on milk vitamins, and evidence for raw milk consumption and other health-related outcomes. J FoodProt 74:1814- 32. https://pubmed.ncbi.nlm.nih.gov/22054181/. 
Mesquita, A. A. et al., (2018). Staphylococcus aureus and Streptococcus agalactiae: prevalence, resistance to antimicrobials, and their relationship with the milk quality of dairy cattle herds in Minas Gerais State, Brazil. Pesquisa Veterinária Brasileira, 39(5), 308-316. http://200.19.146.79/index.php/vetnot/article/view/42513.

Múnera-Bedoya, O. D. et al., (2017). Influence of attitudes and behavior of milkers on the hygienic and sanitary quality of milk. Plos One, 12(9), 0184640345, 19. Public Library of Science (PLoS). http://dx.doi.org/10.1371/journal.pone.0184640.

Nunes O., \& Karnopp E. (2013). Análise das Potencialidades Econômicas Endógenas no Desenvolvimento do Município de Santa Maria/RS. Revista Gestão e Desenvolvimento em Contexto-Gedecon. 1(1). http://revistaeletronica.unicruz.edu.br/index.php/GEDECON/article/download/288/224.

Perobelli, F. S, et al., (2018) Spatial scopes of the milk production chain in Minas Gerais. Nova Economia, 28(1), 297-337. http://www.scielo.br/scielo.php?script=sci_abstract\&pid=S010363512018000100297\&lng=en\&nrm=iso\&tlng=pt.

Picoli T, et al., (2015) Milk production characteristics in Southern Brazil. Semina: Ciências Agrárias, 36(3), 1991-1998.

Pires, M. A. S., Júnior, G. A. D A., \& Lopes, M. A. (2019) Diagnóstico em Propriedades Leiteiras de Economia Familiar em Tabuleiro-MG. Medicina Veterinária (UFRPE), 12(3), 222 231. http://journals.ufrpe.br/index.php/medicinaveterinaria/article/view/2398/482483009\#.

Reis. E. J. (2019) Relatório socioeconômico da cadeia produtiva do leite no Rio Grande do Sul: 2019 / realização: Emater/RS-Ascar., elaboração: Jaime Eduardo Ries. Emater/RSAscar, 2019. 114 p. https://www.ufsm.br/unidades-universitarias/ccr/wp-content/uploads/sites/370/2019/12/RELATORIO-LEITE2019_2.pdf.

Schneider, S. \& Ferrari, D. L. (2015). Cadeias curtas, cooperação e produtos de qualidade na agricultura familiar: o Processo de Re-localização da Produção Agroalimentar em Santa Catarina. Organizações Rurais \& Agroindustriais, 17(1), 56-71. https://www.lume.ufrgs.br/bitstream/handle/10183/1 51097/001010176. pdf?sequence=1.

Schneider, S. (2016) Mercados e Agricultura Familiar. In: MARQUES, F. C., CONTERATO, M. A., SCHNEIDER, S. Construção de Mercados e Agricultura Familiar: Desafios para o Desenvolvimento Rural. UFRGS, 2016. 4. 93-136. file:///C:/Users/Usu\%C3\%A1rio/Downloads/2016-Cap4-SergioSchneider MercadoseAF.pdf.

Silva, M. N et al. (2017). A agricultura familiar e os circuitos curtos de comercialização de alimentos: estudo de caso da feira livre do município de Jaguarão, RS, Brasil. Revista Espacios. 38(47), 7. http://www.revistaespacios.com/a17v38n47/a17v38n47p07.pdf.

Todeschini, B. et al. (2018). Ocorrência de brucelose e tuberculose bovinas no Rio Grande do Sul com base em dados secundários. Pesquisa Veterinária Brasileira, 38(1), 15-22. Fap. UNIFESP (SciELO). http://dx.doi.org/10.1590/1678-5150-pvb-4712.

Werncke, D. et al., (2016) Qualidade do leite e perfil das propriedades leiteiras no sul de Santa Catarina: abordagem multivariada. Arquivo Brasileiro de Medicina Veterinária e Zootecnia, 68(2), 506-516. Fap UNIFESP (SciELO). http://dx.doi.org/10.1590/1678-4162-8396.

Vargas, D. P., Nörnberg, J. L., \& Scheibler, R. B., (2019). Qualidade físico-química e microbiológica do leite bovino em diferentes sistemas de produção e estações do ano. Ciência Animal Brasileira, v. 20, p. e-46898. http://www.scielo.br/scielo.php?script=sci_arttext\&pid=S180968912019000100210\&tlng=pt.

Winch, W. P., Balem, T. A., \& Machado, R. L. (2018). Agroecologia em destaque na produção leiteira: o processo de transição realizado pela Família Santini em Santa Maria-RS. Cadernos de Agroecologia. Anais do VI CLAA, X CBA e V SEMDF. 13(1).

Zagorska J. \& Ciprovica I. Evaluation of Factors Affecting Freezing Point of Milk. (2013). International Journal of Nutrition and Food Engineering. 7(2), 106-111. https://waset.org/publications/15910/evaluation-of-factors-affecting-freezing-point-of-milk. 